\title{
PLATELET-RICH PLASMAPHERESIS IN CARDIAC SURGERY: A META-ANALYSIS OF THE EFFECT ON TRANSFUSION REQUIREMENTS
}

F. D. Rubens, MDa

D. Fergusson, $\mathrm{MHA}^{\mathrm{b}}$

P. S. Wells, $\mathrm{MD}^{\mathrm{b}, \mathrm{c}}$

M. Huang ${ }^{\text {b }}$

J. L. McGowan, MLIS

A. Laupacis, $\mathrm{MD}^{\mathrm{b}, \mathrm{c}}$
Objective: Our purpose was to determine whether intraoperative plateletrich plasmapheresis in cardiac surgery is effective in reducing the proportion of patients exposed to allogeneic red cell transfusions. Methods: A systematic search for prospective, randomized trials of platelet-rich plasmapheresis in cardiac surgery, using MEDLINE, HEALTHSTAR, Current Contents, "Biological Abstracts," and EMBASE/Excerpta Medica up to August 1997, was completed. Trials were included if they reported either the proportion of patients exposed to allogeneic red cells or the units of allogeneic red cells transfused. Trials were abstracted by 2 independent investigators and the quality of trial design was assessed with the use of a validated scale. Results: Seventeen references met the inclusion criteria (1369 patients [675 control: 694 platelet-rich plasmapheresis]). Platelet-rich plasmapheresis reduced the likelihood of exposure to allogeneic red cells in cardiac surgery (odds ratio 0.44 ; $95 \%$ confidence interval $0.27,0.72, P=.001$ ). Platelet-rich plasmapheresis had a small but statistically significant effect on both the volume of blood lost in the first 24 hours (weighted mean difference $-102 \mathrm{~mL} ; 95 \%$ confidence interval $-148,-55 \mathrm{~mL}, P<.0001)$ and the mean units transfused (weighted mean difference $\mathbf{- 0 . 3 3}$ units; $95 \%$ confidence interval $\mathbf{- 0 . 4 3}$, $-0.23, P<.0001)$. However, platelet-rich plasmapheresis was only marginally effective (odds ratio $0.83,95 \%$ confidence interval $0.34,2.01, P=$ .68) for "good" quality trials, whereas it appeared very effective in trials with poor methodologic quality (odds ratio $0.33,95 \%$ confidence interval $0.17,0.62, P=.0007)$. Conclusions: Although platelet-rich plasmapheresis appeared effective in decreasing the proportion of patients receiving transfusions after cardiac operations, the quality of most of the supporting trials was low and the benefit was small in trials of good quality. Further clinical trials should be completed. (J Thorac Cardiovasc Surg 1998;116:641-7)
C oncern about the side-effects of allogeneic blood transfusion, especially the transmission of viral infections, has led to the development of a variety of methods intended to minimize perioperative transfusion in cardiac surgery. These include technologies such as

From the Department of Surgery, University of Ottawa Heart Institute, ${ }^{\mathrm{a}}$ Clinical Epidemiology Unit, Loeb Research Institute, ${ }^{\mathrm{b}}$ and Department of Medicine, University of Ottawa. ${ }^{c}$

Supported in part by a grant from Medtronics Canada, Mississauga, Ontario, Canada.

Received for publication Feb 11, 1998; revisions requested March 24, 1998; revisions received April 22, 1998; accepted for publication June 22, 1998.

Address for reprints: Fraser D. Rubens, MD, MSc, FRCSC, University of Ottawa Heart Institute, 1053 Carling Ave, Ottawa, Ontario, Canada.

Copyright $(\odot) 1998$ by Mosby, Inc.

0022-5223/98 $\$ 5.00+0 \quad \mathbf{1 2 / 1 / 9 2 6 1 0}$ preoperative autologous donation, pharmaceuticals, acute normovolemic hemodilution, cell salvage, and intraoperative platelet-rich plasmapheresis. This last technique involves the prebypass preparation of platelet-rich plasma (PRP) from whole blood. Whereas the separated red cells are readministered to the patient before bypass, the PRP is given after the administration of protamine. With some of the devices used for this technology, the platelets may be concentrated further, thus also allowing for retransfusion of platelet-poor plasma before bypass. Both of these approaches spare the platelets the potential detrimental effects of exposure to the bypass circuit, ${ }^{1}$ which include a decrease in the number of circulating platelets of up to $50 \%$ and abnormal function in the remaining platelets. ${ }^{1}$

The primary objective of this meta-analysis was to determine whether platelet-rich plasmapheresis in car- 
Table I. Trial characteristics

\begin{tabular}{|c|c|c|c|c|c|c|}
\hline \multirow[b]{2}{*}{ First author } & \multirow[b]{2}{*}{ Date } & \multirow[b]{2}{*}{ Type of operation } & \multirow[b]{2}{*}{ Procedure } & \multicolumn{3}{|c|}{ Postop } \\
\hline & & & & ASA preop & transfusion threshold & Jadad score \\
\hline Boldt $^{17}$ & 1990 & Primary & CABG & No patients & Yes & 1 \\
\hline Jones $^{18}$ & 1990 & Primary & CABG & Some patients & Yes & 1 \\
\hline Boey $^{14}$ & 1993 & Primary & CABG & No patients & Yes & 2 \\
\hline Tobe $^{15}$ & 1993 & Primary & CABG & Some patients & No & 5 \\
\hline Boldt $^{16}$ & 1993 & Primary & CABG & No patients & Yes & 2 \\
\hline Ereth $^{20}$ & 1993 & Redo & Valve & Some patients & Yes & 3 \\
\hline Stammers $^{21}$ & 1993 & Primary and redo & CABG and valve & Some patients & Yes & 1 \\
\hline Wong $^{13}$ & 1994 & Primary & $\mathrm{CABG}$ and valve & Some patients & Yes & 2 \\
\hline Quigley ${ }^{10}$ & 1995 & Primary & CABG and valve & Some patients & Yes & 1 \\
\hline Shore- Lesserson ${ }^{11}$ & 1995 & Redo & CABG and valve & Some patients & Yes & 3 \\
\hline Armellin ${ }^{22}$ & 1995 & Primary and redo & $\mathrm{CABG}$ and valve & No patients & Yes & 2 \\
\hline Triulzi $^{12}$ & 1995 & Primary and redo & CABG and valve & Some patients & Yes & 2 \\
\hline Christenson $^{8}$ & 1996 & Redo & CABG & Some patients & Yes & 1 \\
\hline Menges $^{9}$ & 1996 & Primary & CABG & No patients & Yes & 1 \\
\hline Stover ${ }^{5}$ & 1996 & Primary and redo & $\mathrm{CABG}$ and valve & Data not given & No & 1 \\
\hline Armellin ${ }^{7}$ & 1997 & Primary and redo & CABG and valve & Some patients & Yes & 3 \\
\hline Menges $^{19}$ & 1997 & Primary & CABG & No patients & Yes & 1 \\
\hline
\end{tabular}

$C A B G$, Coronary artery bypass grafting; redo, reoperative surgery.

diac surgery is effective in reducing the proportion of patients exposed to allogeneic red cells in the perioperative period. The secondary objectives were to determine whether platelet-rich plasmapheresis is effective in reducing the number of units of allogeneic red cells transfused and the amount of blood lost during the first 24 hours after the operation. The impact of trial methodology on efficacy was also assessed by means of a validated quality assessment scale. ${ }^{2}$

\section{Methods and materials}

Literature search and study selection. Systematic searches of MEDLINE (1966-July 1997), HEALTHSTAR (1995-July 1997), Current Contents (week 1-week 29, 1997), "Biological Abstracts" (1990-March 1997), and EMBASE/Excerpta Medica (1980-1997) were conducted in August 1997 to identify prospective randomized controlled trials. The search strategy was first developed on MEDLINE and then adapted to the controlled vocabulary of each of the other databases. ${ }^{3}$ All titles and abstracts of the identified articles were reviewed by 2 investigators to determine potential eligibility for analysis. Any trial comparing intraoperative platelet-rich plasmapheresis to an appropriate control group, regardless of language or medium of publication, was retrieved for further examination. Platelet-rich plasmapheresis was defined as the process of preparation of autologous platelets from whole blood by means of centrifugation. If insufficient detail was provided in the abstract to determine eligibility, the article was retrieved for further review. Medtronic Inc of Canada (Mississaugua, Ontario) was asked to contribute all articles or reports on this subject from their records. Bibliographies of all identified trials and review articles were hand searched for additional publications.
Authors of trials not reporting either the number of subjects exposed to at least 1 unit of allogeneic red cells or the volume of allogeneic red cells transfused were contacted in an attempt to retrieve the necessary information. Duplicate publications, studies in children, and trials in which the patients were pseudo-randomized were excluded.

Data extraction. Data from each of the studies were independently abstracted onto study data forms by 2 individuals (F.D.R., P.S.W.). Disagreements were resolved by consensus. Non-English language trials were abstracted by 1 of the investigators with the assistance of a translator. No attempt was made to conceal the identity of the author or the medium of the publication. When necessary, authors were contacted in an attempt to clarify results or to provide missing data.

Data abstracted included the proportion of subjects exposed to at least 1 unit of allogeneic red cells in the perioperative period, the type of operation (eg, primary versus reoperative, valve versus coronary artery bypass grafting), the mean units of packed red cells, platelets, and fresh frozen plasma transfused per patient randomized, the mean blood loss within 24 hours of the operation, whether a perioperative transfusion protocol was reported, the preoperative use of aspirin, the preoperative and discharge hematocrit values, and the volume of PRP prepared. In those studies in which this latter volume was recorded as a percentage of the total plasma volume, a conversion factor of $45 \mathrm{~mL} / \mathrm{kg}$ body weight was used to estimate the total PRP collected. ${ }^{4}$ In 1 trial $^{5}$ the volume collected was recorded in units of platelets. This was converted to volume of PRP collected by means of a factor of 55 mL/unit (Clinical Guide to Transfusion; Canadian Red Cross Society, 1987). The methodologic quality of the trials was determined with the use of the scale developed by Jadad and associates. ${ }^{2}$ This scale rates trial design from 0 to 5 depending on subject and investigator blinding, the method of randomization, and the reporting of subject withdrawals. A 
score of 3 or more is considered good quality and a score of less than 3 is considered poor quality. ${ }^{2}$

Analysis. The proportion of patients receiving a transfusion was analyzed with Meta-Analyst (Meta-Analyst ${ }^{0.988}$; Lau J, Chalmers TC, 1995) using Der Simonian and Laird's random effects model. ${ }^{6}$ Results are expressed as odds ratios (OR) with $95 \%$ confidence intervals $(95 \% \mathrm{CI})$. An OR of 1.0 suggests that there was no difference between treatment and control, an OR less than 1.0 indicates that fewer patients in the treatment group (PRP) received allogeneic red cell transfusion, and an OR of greater than 1.0 indicates that more patients in the treatment group received allogeneic red cell transfusion. Tests for heterogeneity were performed for each meta-analysis. If positive, the studies that appeared to be the major contributors to the heterogeneity were evaluated in an attempt to discover the possible reasons. Subgroup analyses based on the type of procedure, volume of blood withdrawn before the operation, transfusion protocol, and pretreatment with aspirin were proposed a priori.

Continuous data, such as the total number of units of allogeneic red cells transfused and the mean blood loss during the first 24 hours after the operation, were analyzed by means of RevMan 1.04b (RevMan 1.04b, The Cochrane Review Manager, 1994), which uses a fixed effects model. Summary results of continuous data are expressed as weighted mean differences (WMD) with $95 \%$ CI.

\section{Results}

The systematic literature searches yielded 1072 references in total. After review of all references, the bibliographies of trials and reviews, and industry literature searches, a total of 19 prospective randomized trials were eligible for analysis. Of the 19 randomized controlled trials, 1 was identified by industry ${ }^{5}$ and 18 were identified by the systematic literature search. Whereas 17 met the inclusion criteria, ,7-22 information on outcomes for 2 trials could not be obtained from either the publication or communication with the authors. ${ }^{23,24}$ The trials included in this meta-analysis included a total of 1369 patients (675 control patients; 694 patients subjected to platelet-rich plasmapheresis). The characteristics of the trials are summarized in Tables I and II.

Of the 17 included trials, 16 trials reported the proportion of patients exposed to at least 1 unit of allogeneic red cells and 15 documented the total number of units of allogeneic red cells transfused. The median sample size of the 17 trials was 44 (range 24-284). The mean volume of PRP collected was $730 \mathrm{~mL}$ (15 trials reporting, range $306-1050 \mathrm{~mL}$ ) and the mean 24-hour blood loss was $821 \mathrm{~mL}$ in the platelet-rich plasmapheresis arm (12 trials reporting, range 481-1514 mL) and $909 \mathrm{~mL}$ in the control arm (range 525-1304 mL).

The effectiveness of platelet-rich plasmapheresis on the proportion of patients receiving allogeneic red cells is shown in Fig 1. When all eligible trials were consid-
Table II. Devices for collection of platelet-rich plas-

\begin{tabular}{|c|c|}
\hline First author & Device* \\
\hline Boldt $^{16}$ & Haemonetics Plasma Collecting System V50 \\
\hline Jones $^{18}$ & Haemonetics Model 5000 \\
\hline Boey ${ }^{14}$ & Haemonetics Plasma Collecting System \\
\hline Tobe $^{15}$ & $\begin{array}{l}\text { Haemonetics Plasma Saver Autologous } \\
\text { Plasma Collection System }\end{array}$ \\
\hline Boldt $^{17}$ & Haemonetics Plasma Collecting System V50 \\
\hline Ereth $^{20}$ & Haemonetics Plasma Saver \\
\hline Stammers $^{21}$ & Haemonetics Plasma Saver \\
\hline Wong $^{13}$ & Haemonetics Plasma Saver \\
\hline Quigley ${ }^{10}$ & Haemonetics Cell Saver IV \\
\hline Shore-Lesserson ${ }^{11}$ & Haemonetics Plasma Saver \\
\hline Armellin ${ }^{7}$ & Haemonetics Ultralite \\
\hline Triulzi ${ }^{12}$ & Haemonetics Plasma Saver \\
\hline Christenson $^{8}$ & $\begin{array}{l}\text { Electromedics Elmd-500 Autotransfusion/ } \\
\text { Platelet Sequestration Device }\end{array}$ \\
\hline Menges ${ }^{9}$ & Haemonetics Plasma Collecting System V250 \\
\hline Stover $^{5}$ & Electromedics AT 1000 \\
\hline Armellin 22 & Haemonetics Ultralite \\
\hline Menges $^{19}$ & Haemonetics \\
\hline
\end{tabular}

*Haemonetics Corporation, Braintree, Massachusetts. Electromedics Inc, Parker, Colorado.

ered, platelet-rich plasmapheresis significantly reduced the likelihood of exposure to at least 1 unit of allogeneic red cells (OR 0.44; 95\% CI 0.27, 0.72; $P=$ .0012). Platelet-rich plasmapheresis reduced the number of units of allogeneic red cells transfused (WMD -0.33 units; $95 \%$ CI $-0.43,-0.23$ ). Twelve of the studies provided sufficient information for the determination of the total 24-hour blood loss from the mediastinal tubes. Platelet-rich plasmapheresis had a small but statistically significant effect on the volume of blood lost in the first 24 hours of the perioperative period (WMD -102 mL; 95\% CI -148, $-55 \mathrm{~mL} ; P=.00002$ ).

Marked heterogeneity was found in the primary outcome analysis of the proportion of patients receiving allogeneic red cells $\left(\chi^{2} 47.1 ; 15\right.$ degrees of freedom; $P<$ $.001)$, as well as the secondary outcomes, 24-hour blood loss $\left(\chi^{2} 33.0 ; 11\right.$ degrees of freedom; $\left.P<.001\right)$, and mean units transfused $\left(\chi^{2} 61.2 ; 10\right.$ degrees of freedom; $P<.001)$.* Subgroups were analyzed to better clarify the potential causes of this heterogeneity. The variables examined in the subgroups were defined a priori and included the surgical procedure, the proportion of patients receiving acetylsalicylic acid, the transfusion threshold, the amount of platelet plasma volume collected, and the methodologic quality of the trials (Fig 2).

*A $\chi^{2}$ for mean units could not be calculated for the 15 studies because 4 studies had standard deviations of 0 . Therefore a $\chi^{2}$ for homogeneity was calculated for 11 studies. 


\begin{tabular}{|c|c|c|}
\hline \multirow[t]{2}{*}{ Author } & \multicolumn{2}{|c|}{ Patients Transfused } \\
\hline & Treatment & Control \\
\hline Boldt & $0 / 15$ & $2 / 15$ \\
\hline Jones & $17 / 50$ & $34 / 50$ \\
\hline Boldt & $0 / 12$ & $3 / 12$ \\
\hline Ereth & $25 / 28$ & $27 / 28$ \\
\hline Stammers & $25 / 63$ & $42 / 52$ \\
\hline Tobe & $17 / 24$ & $19 / 27$ \\
\hline Wong & $6 / 19$ & $5 / 19$ \\
\hline Armellin & $59 / 128$ & $86 / 128$ \\
\hline Quigley & $33 / 64$ & $21 / 52$ \\
\hline Shore-Lesserson & $22 / 25$ & $13 / 19$ \\
\hline Triulzi & $8 / 24$ & $10 / 28$ \\
\hline Christenson & $1 / 20$ & $14 / 20$ \\
\hline Menges & $0 / 20$ & $5 / 20$ \\
\hline Stover & $4 / 21$ & $11 / 23$ \\
\hline Armellin & $69 / 142$ & $93 / 142$ \\
\hline Menges & $0 / 20$ & $5 / 20$ \\
\hline
\end{tabular}

Overall

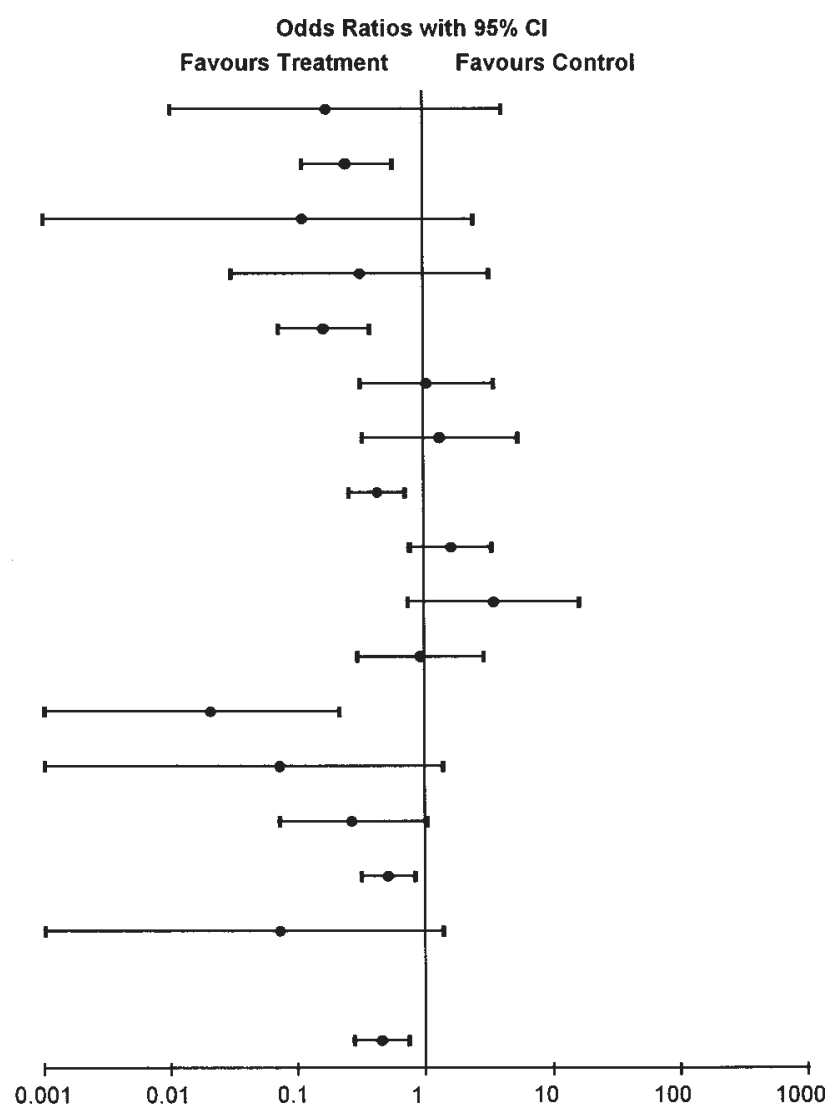

Fig 1. Platelet-rich plasmapheresis in cardiac surgery: Proportion of patients receiving transfusions of allogeneic red cells. $C I$, Confidence interval.

For the primary outcome of the proportion of patients receiving a transfusion of allogeneic red cells, there was no evidence of a difference in efficacy among the subgroups (Fig 2). There was a nonsignificant trend for trials with poor methodology to yield larger effect sizes. Additionally, there was a nonsignificant trend toward trials with higher postoperative transfusion thresholds and higher collected platelet plasma volumes to demonstrate a smaller treatment effect. Subgroup analysis was performed for mean units transfused and the blood loss within 24 hours of the operation, and no differences were found that would explain the heterogeneity (results not shown).

The rate of transfusion in the control group ranged between $13 \%$ and $96 \%$ in patients undergoing cardiac operations. Little correlation was observed between the proportion of patients receiving an allogeneic transfusion in the control group and the absolute risk reduction caused by platelet-rich plasmapheresis $(R 2=0.0214)$.

\section{Discussion}

In this meta-analysis of patients undergoing cardiac surgery, intraoperative platelet-rich plasmapheresis was found to significantly decrease the proportion of patients receiving a transfusion in the perioperative period. Two secondary outcomes, mean units of allogeneic red cells transfused and mean blood loss within 24 hours of the operation, were also found to be significantly decreased in the experimental group compared with the control group.

However, a marked heterogeneity was observed in the results of the studies included in the meta-analysis. Numerous subgroup analyses performed for all 3 outcomes did not convincingly establish the reason for this heterogeneity (Fig 2). Because of the significant unexplained heterogeneity, caution must be exercised in recommending this technology without further large, high-quality randomized trials that clearly demonstrate benefit. Furthermore, the only trial in this meta-analysis that achieved a perfect methodologic score of 5 on the Jadad scale had an OR of 1.02 (95\% CI 0.31, 3.42), which suggested that platelet-rich plasmapheresis was not effective. ${ }^{15}$

It was puzzling to find that the efficacy of platelet-rich plasmapheresis was inversely related to the volume of platelets collected (Fig 3). However, several other 


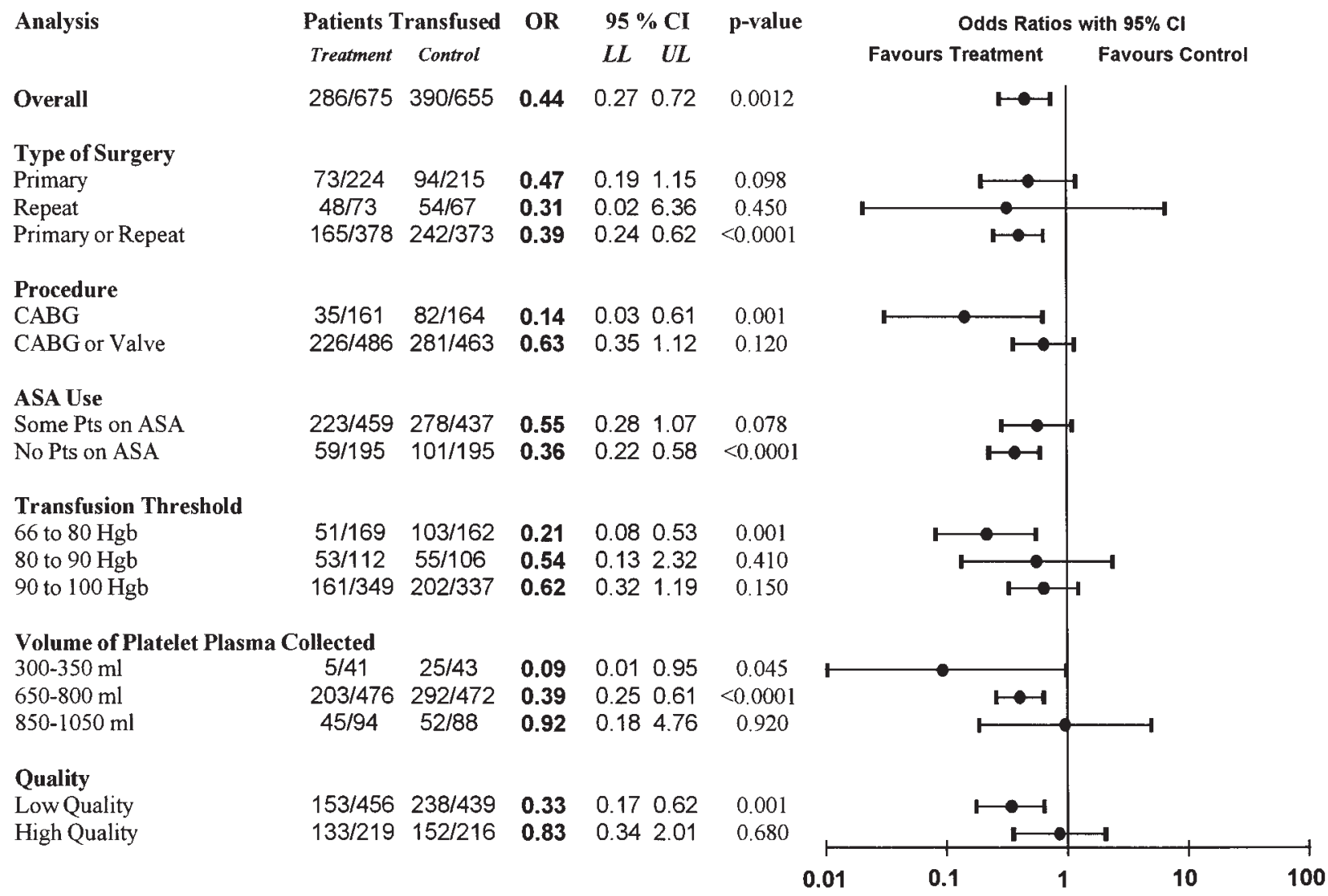

Fig 2. Proportion of patients receiving transfusions of allogeneic red cells: Subgroup analyses. $C A B G$, Coronary artery bypass grafting. $A S A$, acetylsalicylic acid; $H g b$, hemoglobin; $O R$, odds ratio; $C I$, confidence interval; $L L$, lower limit; $U L$, upper limit.

authors have already suggested that the most important factor contributing to efficacy is the absolute number of platelets collected, not their volume. ${ }^{25,26}$ In 2 of the trials $^{5,8}$ reported in this meta-analysis, in which between 300 and $350 \mathrm{~mL}$ of PRP was collected (OR 0.09; 95\% CI $0.01-0.9 ; P=.045$ ), a 2-speed centrifugation technique was used (AT1000; Electromedics Inc, Parker, Colo), which is known to produce a platelet-rich concentrate equivalent to 6 units of platelets. ${ }^{26}$ In 7 of the 17 trials, we were able to calculate, a posteriori, the number of platelets extracted. There appeared to be a correlation between efficacy and the number of platelets extracted, although this correlation was not tested statistically (Fig 3). This finding should be viewed with considerable caution because this was a post hoc subgroup analysis conducted on a small number of patients. ${ }^{27}$

Other factors may influence the efficacy of this technology. First, platelet function is significantly impaired after centrifugation, and the platelets may be refractory to stimulation for a period of 4 to 6 hours. ${ }^{28}$ Second, although this technology decreased the volume of postoperative shed mediastinal blood compared with that of the control group (WMD $-102 \mathrm{~mL}[-148,-55 \mathrm{~mL}]$ ), it cannot limit the intraoperative blood loss that occurs during cardiopulmonary bypass. This loss is particularly important with reoperative surgery because of vascular adhesions and contributes to the increased transfusion requirements in this population.

In the 1 trial that recorded complications related to platelet-rich plasmapheresis, ${ }^{11}$ some of the patients had hypotension and several had to be excluded from the study before the completion of PRP collection as a result of hemodynamic instability. This instability may have been related to inadequate fluid replacement during the withdrawal of whole blood, leading to hypovolemia.

Limitations of this meta-analyses must be addressed. Caution must be exercised when looking at the results of meta-analyses with small sample sizes. Meta-analyses of other interventions, such as magnesium and nitrates for patients with myocardial infarction, have reached false positive conclusions about efficacy when their results were compared with a subsequent "definitive" large trial. ${ }^{29}$ Second, there was a large amount of heterogeneity between the trials analyzed, which was not explained by subgroup analyses. However, the lack of an explanation may have been related to the fact that 


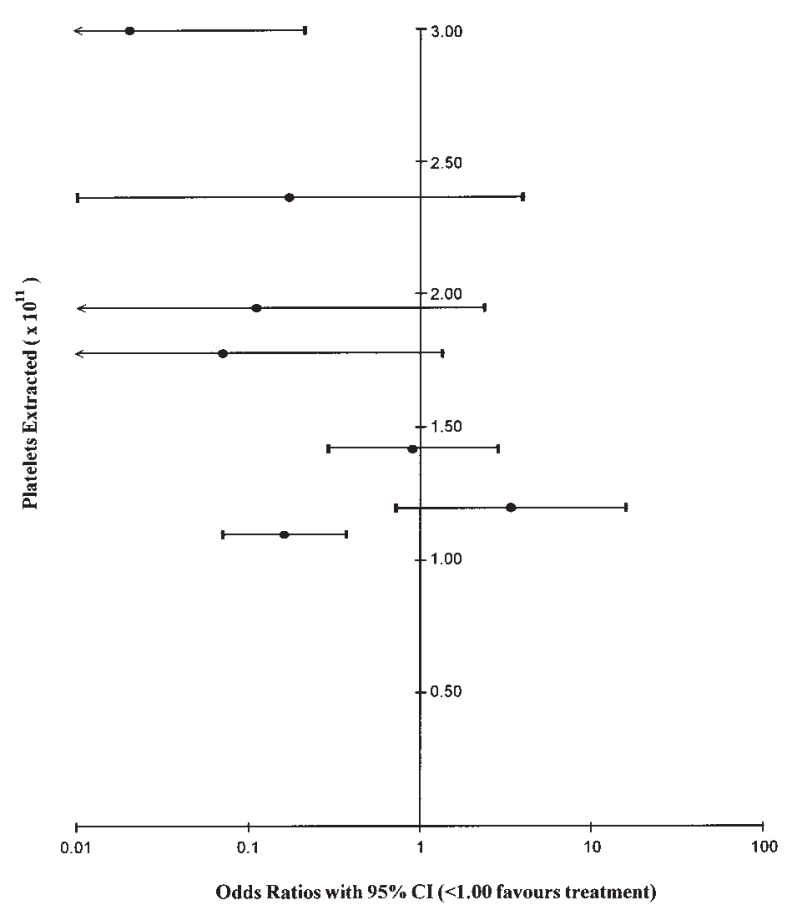

Fig 3. Effect size (proportion receiving allogeneic red cells) versus total platelets extracted. CI, Confidence interval.

the subgroups were too small to allow statistically significant answers to be found. Finally, not all studies reported both the primary and secondary outcomes; thus only a subset, albeit a majority of the identified trials, were included in the analysis. Similarly, only a handful of trials reported adverse events. This supports the recommendations that uniform and comprehensive standards are needed when reporting results of trials of blood conservation technologies. ${ }^{30}$

In conclusion, the overall OR found in this metaanalysis suggests that the proportion of patients receiving a transfusion was decreased in patients in whom platelet-rich plasmapheresis was used in cardiac surgery. This was associated with a decrease in the total volume of transfused allogeneic red cells and a small but statistically significant decrease in the total shed mediastinal blood. However, the poor methodologic quality of most of the trial reports and the marked heterogeneity of the results make it very difficult to determine the true efficacy of platelet-rich plasmapheresis. A large, double-blind, randomized, controlled trial is needed to further delineate the role of intraoperative platelet-rich plasmapheresis in cardiac surgery.

We thank Dr. Howard Nathan for reviewing the manuscript, as well as Drs. Tsuneo Ogawa and Ioulia Doumkina for their assistance with translation.

\section{REFERENCES}

1. Campbell FW. The contribution of platelet dysfunction to postbypass bleeding. J Cardiothorac Vasc Anaesth 1991;5:8-12.

2. Jadad AR, Moore A, Carroll D, Jenkinson C, Reynolds DJM, Gavaghan DJ. Assessing the quality of reports of randomized clinical trials: Is blinding necessary? Control Clin Trials 1996;17:1-12.

3. Haynes RB, Wilcqynaski N, McKibbon KA, Walker CJ, Sinclair JC. Developing optimal search strategies for detecting clinically sound studies in MEDLINE. J Am Med Inform Assoc 1994;1:447-58.

4. Dacie JV, Lewis SM. Collection and handling of blood. In: Dacie JV, Lewis SM, editors, Practical haematology, 7 ed. Edinburgh: Churchill Livingstone; 1991. p. 1-7.

5. Stover EP, Siegel LC, Hood PA, O'Riordan GE. Platelet-rich plasmapheresis with therapeutic platelet yield reduces allogeneic red blood cell and platelet transfusions in high-risk cardiac surgery [abstract]. Anesthesiology 1996;85.

6. Berlin JA, Laird NM, Sacks HS, Chalmers TC. A comparison of statistical methods for combining event rates from clinical trials. In: Anonymous statistics in medicine. John Wiley; 1989. p. 14151.

7. Armellin G, Sorbara C, Bonato R, Pittarello D, Dal Cero P, Giron G. Intraoperative plasmapheresis in cardiac surgery. J Cardiothorac Vasc Anaesth 1997;11:13-7.

8. Christenson JT, Reuse J, Badel P, Simonet F, Schmuziger M. Plateletpheresis before redo CABG diminishes excessive blood transfusion. Ann Thorac Surg 1996;62:1373-9.

9. Menges T, Wagner RM, Welters I, Ruwoldt R, Boldt J, Hempelmann G. The role of the protein C-Thrombomodulin system and fibrinolysis during cardiovascular surgery: influence of acute preoperative plasmapheresis. J Cardiothorac Vasc Anaesth 1996;10:482-9.

10. Quigley RL, Perkins JA, Caprini JA, et al. The haemostatic effectiveness of autologous platelet rich plasma sequestered after heparin administration and institution of cardiopulmonary bypass. Perfusion 1995;10:101-10.

11. Shore-Lesserson L, Reich DL, DePerio M, Silvay G. Autologous platelet-rich plasmapheresis: risk versus benefit in repeat cardiac operations. Anesth Analg 1995;81:229-35.

12. Triulzi DJ, Gilmor GD, Ness PM, Baumgartner WA, Schultheis LW. Efficacy of autologous fresh whole blood or platelet-rich plasma in adult cardiac surgery. Transfusion 1995;35:627-34.

13. Wong CA, Franklin ML, Wade LD. Coagulation tests, blood loss, and transfusion requirements in platelet-rich plasmapheresed versus nonpheresed cardiac surgery patients. Anesth Analg 1994;78:29-36.

14. Boey SK, Dhara SS. Preoperative plateletpheresis does not reduce blood loss during cardiac surgery. Can J Anaesth 1993;40:844-50.

15. Tobe CE, Vocelka C, Sepulvada R, et al. Infusion of autologous platelet rich plasma does not reduce blood loss and product use after coronary artery bypass. Cardiovasc Surg 1993;105:1007-14.

16. Boldt J, Zickmann B, Ballesteros M, Oehmke S, Stertmann F, Hempelmann G. Influence of acute preoperative plasmapheresis on platelet function in cardiac surgery. J Cardiothorac Vasc Anaesth 1993;7:4-9.

17. Boldt J, vonBormann B, Kling D, Jacobi M, Moosdorf R, Hempelmann G. Preoperative plasmapheresis in patients undergoing cardiac surgery procedures. Anesthesiology 1990;72:282-8.

18. Jones JW, McCoy TA, Rawitscher RE, Lindsley DA. Effects of 
intraoperative plasmapheresis on blood loss in cardiac surgery. Ann Thorac Surg 1990;49:585-90.

19. Menges T, Welters I, Wagner RM, Boldt J, Dapper F, Hempelmann G. The influence of acute preoperative plasmapheresis on coagulation tests, fibrinolysis, blood loss and transfusion requirements in cardiac surgery. Eur J Cardiothorac Surg 1997;11:557-63.

20. Ereth MH, Oliver WC, Beynen FMK, et al. Autologous plateletrich plasma does not reduce transfusion of homologous blood products in patients undergoing repeat valvular surgery. Anesthesiology 1993;79:540-7.

21. Stammers AH, Kratz J, Johnson T, Crumbley J, Merrill J. Hematological assessment of patients undergoing plasmapheresis during cardiac surgery. J Extracorp Technol 1993;25:6-14.

22. Armellin G, Sorbara C, Bonato R, Pittarello D, Toniolo E, Giron GP. Effects of acute intraoperative plasmapheresis in cardiac surgery. Acta Anaesth Ital 1995;46:17-22.

23. Ferraris VA, Berry WR, Klingman RR. Comparison of blood reinfusion techniques used during coronary artery bypass grafting. Ann Thorac Surg 1993;56:433-40.

24. DelRossi AJ, Cernaianu AC, Vertrees RA, et al. Platelet-rich plasma reduces postoperative blood loss after cardiopulmonary bypass. J Thorac Cardiovasc Surg 1990;100:281-6.

25. Davies GG, Ruffcorn M, Dooley JB, Mabee TM, Sadler R, Samelson S. Plateletpheresis before cardiopulmonary bypass. I. Anesthesiology 1994;80:714.

26. Davies GG, Wells DG, Mabee TM, Sadler R, Melling NJ. Platelet-leukocyte plasmapheresis attenuates the deleterious effects of cardiopulmonary bypass. Ann Thorac Surg 1992; 53:274-7.

27. Oxman AD, Guyatt GH. A consumer's guide to subgroup analyses. Ann Intern Med 1992;116:78-84.

28. Gutensohn K, Bartsch N, Kuehnl P. Flow cytometric analysis of platelet membrane antigens during and after continuous-flow plateletpheresis. Transfusion 1997;37:809-15.

29. Brzak S, Ridker PM. Discordance between meta-analyses and large-scale randomized, controlled trials. Ann Intern Med 1995; $123: 873-7$.

30. Lemmer JH. Reporting the results of blood conservation studies: the need for uniform and comprehensive methods. Ann Thorac Surg 1994;58:1305-6.

\section{Bound volumes available to subscribers}

Bound volumes of The Journal of Thoracic and Cardiovascular Surgery are available to subscribers (only) for the 1998 issues from the Publisher, at a cost of $\$ 122.00$ for domestic, $\$ 151.94$ for Canadian, and $\$ 142.00$ for international subscribers for Vol 115 (January-June) and Vol 116 (July-December). Shipping charges are included. Each bound volume contains a subject and author index and all advertising is removed. Copies are shipped within 60 days after publication of the last issue of the volume. The binding is durable buckram with the Journal name, volume number, and year stamped in gold on the spine. Payment must accompany all orders. Contact Mosby, Inc, Subscription Services, 11830 Westline Industrial Drive, St Louis, MO 63146-3318, USA; phone 800-453-4351 or 314-453-4351.

Subscriptions must be in force to qualify. Bound volumes are not available in place of a regular Journal subscription. 